\title{
Changes of the potential distribution area of French Mediterranean forests under global warming
}

\author{
C. Gaucherel ${ }^{1}$, J. Guiot ${ }^{2}$, and L. Misson ${ }^{3}$ \\ ${ }^{1}$ INRA, UMR AMAP, TA A.51/PS2, 34398, Montpellier, France \\ ${ }^{2}$ CEREGE - UMR 6635 CNRS Aix-Marseille Université - BP 80, 13545 Aix-en-Provence Cedex 4, France \\ ${ }^{3}$ CEFE - UMR 5175 CNRS, 1919 Route de Mende, 34293 Montpellier Cedex 5, France
}

Received: 14 November 2007 - Published in Biogeosciences Discuss.: 8 February 2008

Revised: 2 July 2008 - Accepted: 21 July 2008 - Published: 4 November 2008

\begin{abstract}
This work aims at understanding future spatial and temporal distributions of tree species in the Mediterranean region of France under various climates. We focused on two different species (Pinus Halepensis and Quercus Ilex) and compared their growth under the IPCC-B2 climate scenario in order to quantify significant changes between present and future. The influence of environmental factors such as atmospheric $\mathrm{CO}_{2}$ increase and topography on the tree growth has also been quantified.

We modeled species growth with the help of a processbased model (MAIDEN), previously calibrated over measured ecophysiological and dendrochronological series with a Bayesian scheme. The model was fed with the ARPEGE - MeteoFrance climate model, combined with an explicit increase in $\mathrm{CO}_{2}$ atmospheric concentration. The main output of the model gives the carbon allocation in boles and thus tree production.

Our results show that the MAIDEN model is correctly able to simulate pine and oak production in space and time, after detailed calibration and validation stages. Yet, these simulations, mainly based on climate, are indicative and not predictive. The comparison of simulated growth at end of 20th and 21 st centuries, show a shift of the pine production optimum from about 650 to $950 \mathrm{~m}$ due to $2.5 \mathrm{~K}$ temperature increase, while no optimum has been found for oak. With the direct effect of $\mathrm{CO}_{2}$ increase taken into account, both species show a significant increase in productivity $(+26$ and $+43 \%$ for pine and oak respectively) at the end of the 21 st century.

While both species have different growth mechanisms, they have a good chance to extend their spatial distribution and their elevation in the Alps during the 21 st century under
\end{abstract}

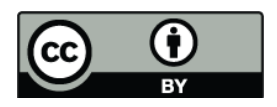

Correspondence to: C. Gaucherel (gaucherel@cirad.fr) the IPCC-B2 climate scenario. This extension is mainly due to the $\mathrm{CO}_{2}$ fertilization effect.

\section{Introduction}

Forest productivity and distribution changes in the coming decades are a major concern of ecological studies. Differential impacts of global climatic changes or increasing atmospheric $\mathrm{CO}_{2}$ concentration, as well as complex vegetation feedbacks on climate makes it hard to estimate the vegetation patterns in future (Prentice and Webb, 1998; Sitch et al., 2003). It is particularly true in Mediterranean region which has a limited area but with a high diversity of environments, vegetation and fauna (Joffre et al., 1999). Forests in this region are crucial for preserving this biodiversity and provide essential ecosystem services, such as soil protection, water conservation and climate regulation (Eamus et al., 2005). Circulation models predict a significant warming and decrease in precipitation in the Mediterranean basin (Gibelin and Deque, 2003). Giorgi (2006) identified the Mediterranean basin as the most prominent hot-spot of climate change over the world with more than $20 \%$ decline of precipitation over April to September. Precipitation and drought risk changes can trigger a positive feedback on climate change by decreasing $\mathrm{CO}_{2}$ sequestration in ecosystems (Ciais et al., 2005).

Assessment of climatic change impacts must be supported by accurate and reliable models of climate-vegetation growth relationships (Misson, 2004; Misson et al., 2004; Rathgeber et al., 2003). These models must be carefully calibrated and validated on data at different time and space scales. At large spatial scales, these data may come from field-based studies on natural gradients (Rathgeber et al., 2005). To

Published by Copernicus Publications on behalf of the European Geosciences Union. 
include the time variability at these gradient, dendrochronological series are valuable as an exploratory tool for identifying relevant climatic variables and periods when tree growth is responding to climate (Tessier, 1989) or as a support to modelling (Misson, 2004; Rathgeber et al., 2005, 2000). At smaller space and time scale, field data (Rathgeber et al, 2005) and/or coupled micro-meteorological and biogeochemical data measured at fine resolution in forest stations (Misson, 2004) are essential to understand eco-physiological processes of the water and carbon cycles in the ecosystem.

Modelling approaches are diverse. Some of them have focused either on ecophysiological processes (Anselmi et al., 2004) or on spatial patterns by the use of statistical relationships (Luoto et al., 2005; Thuiller et al., 2004). We intend here to simultaneously investigate both issues. We explore the geographical distribution of two common Mediterranean species: Aleppo pine (Pinus halepensis M.) and evergreen Holm oak (Quercus ilex L.) by using an ecophysiological model (MAIDEN, (Misson et al., 2004) that has been calibrated independently (Gaucherel et al., 2008) for both species using a Bayesian approach. This model is driven here, for the South-East France region, by climate simulations for the 21st century, at the daily time step using the Global Climate Model ARPEGE for the IPCC-B2 scenario (Deque et al., 1994). In addition, the fertilization effect of $\mathrm{CO}_{2}$ is assessed by comparing simulations with constant and with variable $\mathrm{CO}_{2}$ concentration.

Our main assumptions for this work are common to other similar works (Yu et al., 2002): forests are mature, they do not genetically adapt to climatic changes, their colonization process is quick enough relatively to climate changes to neglect their population dynamics. Moreover, we only focus on potential distribution areas, neglecting human impacts (Debussche et al., 1999). The objectives of this work are threefold: i) to estimate the tendency of both Mediterranean species growth for the 21 st century and to compare them to the past (20th century) in order to detect significant changes; ii) to quantify the influence of environmental factors such as $\mathrm{CO}_{2}$ increase on the tree growth according to the topography, the other external factors, such as soil composition, being considered as fixed and uniform over the entire region; iii) to quantitatively compare both species behavior regarding to climate/topography/ $\mathrm{CO}_{2}$ concentration changes, thus helping to extrapolate our results.

\section{Data and materials}

\subsection{Dendrochronological and ecophysiological data}

We use dendrochronological data from 21 Aleppo pine (P. halepensis) stands (Nicault, 1999) and one typical Holm oak $(Q$. ilex) stand (unpublished data sampled in the Puéchabon site (Rambal et al., 2003)). All sites are located on calcareous soil in PACA region (Long. $0-8^{\circ} \mathrm{N} \times$ Lat. 41.5- $46.5^{\circ} \mathrm{N}$ ), southeast France. The pine tree-ring series are based on the annual earlywood width $\left(E_{w}\right)$, the latewood width $\left(L_{w}\right)$, the earlywood density $\left(E_{d}\right)$ and the latewood density $\left(L_{d}\right)$, which are combined into a biomass index, $W(t)=E_{w}(t) . E_{d}(t)+L_{w}(t) . L_{d}(t)$, taking into account for both stem radial growth and wood density (Rathgeber et al., 2000). The $W(t)$ curve of oak is calculated on the ring widths only as density measurements are not available. Ring width series are indexed using a digital filter as it is usually done in dendroclimatology (Cook and Kairiukstis, 1990). The oak tree-ring chronology was built by sampling 15 stem disks from 15 trees, among which only seven were kept. Because of the eccentricity of the stem, only the longest radius was measured in each disk. The tree-ring width chronologies on these 15 disks were interdated 2 by 2 in order to give the exact year for each tree ring. Ring with very high and very low width help us interdating the chronologies, as well as rings showing some cell disruption because of very low winter temperature that damaged the cambium (1963, 1985 and 1987). Tree-ring chronologies have been averaged into a 32-year regional chronology (1963-1994) in order to avoid over-parameterization and to perform a rigorous calibration. These 32 years are the common years for all sites. The 38year oak series (1968-2005) is more local as it is based on a single site. Both mean series will be used to calibrate some parameters of the MAIDEN tree-growth model. Botanical, ecological and topographical factors were also recorded at each stand (Rathgeber et al., 2005) and used to help in calibrating several physiological processes. Two years, 1956 and 1985, are characterized by extremely low winter temperature for the region (much below the freezing level), which induced partial damaging of the cambium and had strong impacts on the growth during three years. As these processes are not integrated in the model, years 1956-1958 and 19851987 have been removed from the dataset.

In addition, we used the averaged biomass index of each 21 stands over the first 50 years (R50) of each site as an index of the unbiased fertility of the stand. R50 is computed by summing $\mathrm{W}(\mathrm{t})$ of each tree over the first 50 years and then averaging them over the stand. Although this index could still be influenced by stand density, it offers a synthetic idea of the spatial distribution of pine production (Rathgeber et al., 2005). At two sites, one in P. halepensis and one in $Q$. ilex, tree transpirations were measured continuously at $1 / 2 \mathrm{~h}$ time step for one year using the heat dissipation method (Granier, 1987). Xylem sap flux density $\left(\mathrm{H}_{2} \mathrm{Oh}^{-1} \mathrm{dm}^{-2}\right.$ sapwood) was monitored on 6 trees in the two plots. The sampled trees were representative of the plots' mean basal area tree circumference. The sap flow sensors consist in a pair of probes, $2 \mathrm{~cm}$ long and $0.2 \mathrm{~cm}$ in diameter each, inserted in a radial orientation separated vertically by $12 \mathrm{~cm}$ behind the cambial zone. The temperature difference between the heated and reference probes $(\Delta T)$ was recorded and sap flux density was calculated according to Granier (1985). Up-scaling from tree to stand was based on the estimation of the stand sapwood area. 


\subsection{Ecophysiological model}

The process-based tree-growth model MAIDEN is extensively described in Misson (2004); Misson et al. (2004); Vincke et al. (2005). The model calculates processes such as photosynthesis, stomatal conductance and carbon allocation. The water balance is computed at the ecosystem level, including canopy water interception, transpiration, soil evaporation, soil water transfer, drainage and runoff. MAIDEN separates daily net primary production (NPP) between carbon reservoirs (leaf, bole, root and storage) according to phenological phase-dependent rules. These phases are (1) winter: no activity, (2) spring: leaf and root expansion, (3) summer: bolewood production, (4) early falls: carbohydratereserve accumulation, (5) late fall: leaf and root senescence. An original modeling procedure of carbon storage and mobilization was developed to reproduce the temporal autocorrelation structure of tree-ring series (Guiot, 1986). The annual increment of bole carbon reservoir at stand level is the modeled variable that will be compared with the observed dendrochronological tree-ring series. To be applied to a given species at a given site, the model needs several input variables such as altitude, latitude, maximum absolute Leaf Area Index (LAI), specific leaf area, initial bole biomass, soil thickness and soil textural classes, which can be obtained from site measurements. Moreover, it also needs eleven internal parameters that can be tuned to fit at best available ecophysiological and dendrochronological data, as explained in Gaucherel et al. (2008). Climatic driving variables are daily minimum and maximum temperature and precipitations. MAIDEN uses the MT-CLIM algorithm (Running et al., 1987) to estimate daily solar radiation and vapor pressure deficit from daily temperature and precipitations.

\subsection{Climatic scenarios}

Observed daily temperatures and precipitation series are obtained from the METEO-France meteorological station of Aix-en-Provence. Climatic simulations for the 20th and 21th centuries are obtained from the global climate model ARPEGE-IFS (hereafter APG (Gibelin and Deque, 2003)) driven by the IPCC-B2 scenario radiative forcing (including greenhouse gases, $\mathrm{CO}_{2}, \mathrm{CH}_{4}, \mathrm{~N}_{2} \mathrm{O}, \mathrm{CFC}$, water vapor, ozone, and five types of aerosols). Doubling of atmospheric $\mathrm{CO}_{2}$ concentration occurs towards the end of the 21 st century with $610 \mathrm{ppm}$, while the 20th century concentrations are the observed values. Description of the model is given in Deque et al. (1994) and Gibelin and Deque (2003). The APG model, for which the time step is $30 \mathrm{~min}$, provides daily maximum and minimum air temperatures as well as daily precipitations for the 1960-2099 period. The grid point used has a $0.5^{\circ} \times 0.5^{\circ}$ cell size that we have interpolated as a function of latitude and longitude using a two-dimensional (2-D) bicubic technique.
We used the Climate Research Unit (CRU) gridded dataset (New et al., 1999) over the 1960-1998 control period to estimate possible biases of the APG simulation and correct it during the 21 st century. This surface climatology has also a $0.5^{\circ} \times 0.5^{\circ}$ resolution and has been interpolated for visualisation comfort in the same way than the APG fields. Although having the same resolution, the CRU grid does not perfectly superimpose with the APG grid: to obtain comparable data over the whole region, temperature and precipitation fields have been systematically corrected by associating the nearest grid points between the two grids (thus without any interpolation). The maximum and minimum temperature and precipitation fields simulated by the APG model are finally compared with the 1960-1998 CRU climatology over South East France (New et al., 1999). In addition, the regional topography is available with gridpoints ranging from 0 to $2200 \mathrm{~m}$ elevation in Pyrenees and Alps mountains.

\section{Methods}

\subsection{Ecophysiological calibration and simulation}

Bayesian techniques such as Monte Carlo Markov Chains (MCMC) offer the opportunity to estimate the (a posteriori) distribution of the calibration parameters, starting from their predefined (a priori) statistical distributions (Andrieu et al., 2001; Gelman et al., 1995). We basically proceeded in two main stages (details on the calibration are given in Gaucherel et al., 2008). The a priori distributions are assumed to be uniform with a very large range. First, the range of six parameters controlling the ecophysiological processes has been narrowed by using the MCMC algorithm and the transpiration observations available for both species. This method provided us with an a posteriori probability distribution and then a $90 \%$ confidence interval for each parameter. The limits of this interval have been used to define the a priori limits used in the second stage in which the eleven parameters (the six ones calibrated in the first stage, plus the five remaining ones related to carbon allocation processes) have been calibrated on the observed dendrochronological time series. For each calibration, adapted convergence tests proposed by the BUGS project (Spiegelhalter et al., 1993) have been implemented. We performed detailed elasticity tests of the model to estimate possible misspecifications of model's components, as well as validation on independent meteorological data to detect possible over-parameterization (Gaucherel et al., 2008). Finally, the model fit (determination coefficient $r^{2}$ ) between observations and simulation modes, after five draws of 5000 steps each, converges and summarizes the modeling efficiency.

The eleven parameters are species dependent and valid for the whole region. After the calibration stage, only climatic variables and $\mathrm{CO}_{2}$ atmospheric concentration vary in time. Other parameters are site dependent: soil properties, 

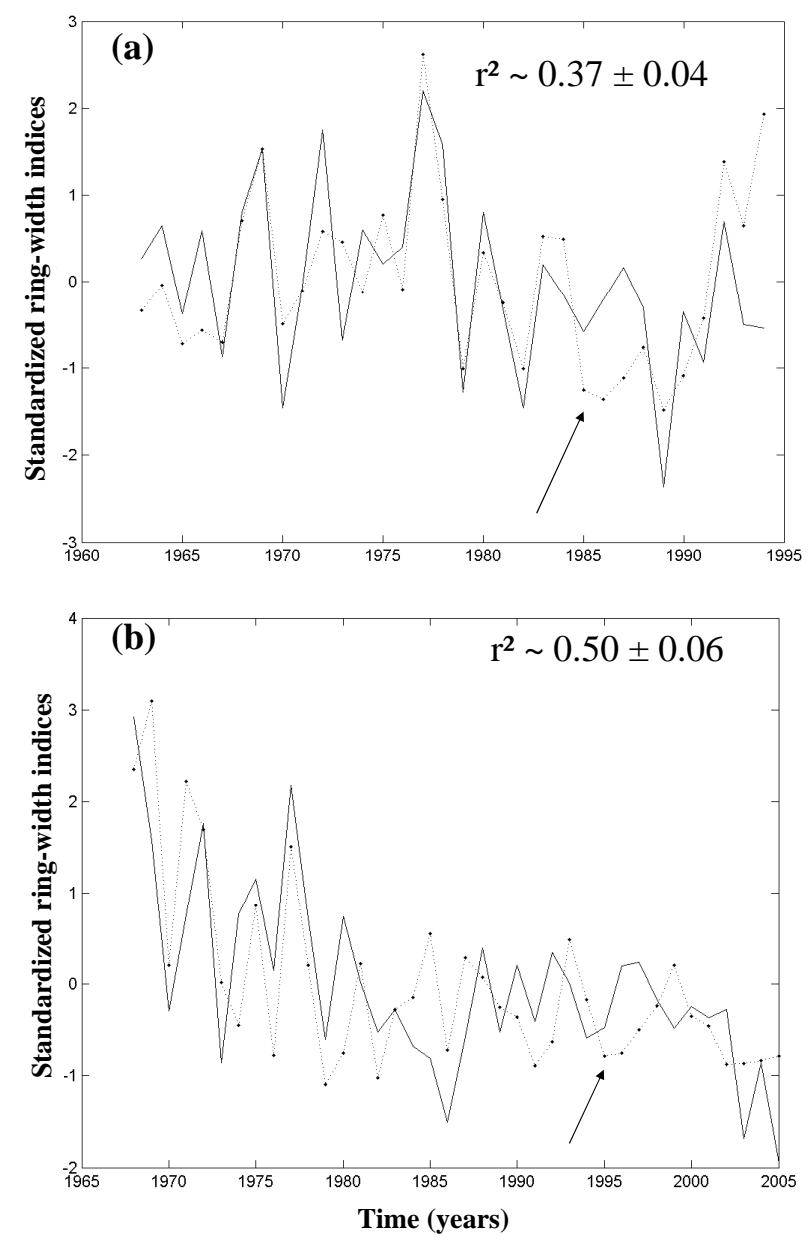

Fig. 1. Indexed tree-ring series (dotted line) and bole carbon allocation simulated by MAIDEN model after MCMC calibration (plain line) (a) Regional Aleppo pine (Pinus Halepensis) dendrochronology averaged over 21 series and (b) evergreen oak series at Puechabon site. Both simulations are based on a calibration stage obtained after the convergence of five draws (5000 steps each). Arrows show excluded years (1985-1986).

topography, elevation and coordinates (for radiative process estimation). We choose averaged regional soil textures for the four soil layers (being 10, 20, 20 and $10 \mathrm{~cm}$ deep respectively): percentages of clay $(25,30,35,35$ resp.) and sand $(10,15,20,20$ resp.) (Misson et al., 2004). Ecophysiological simulations are made for mature stands such that the only biomass gain between years is caused by the bole carbon allocation. The $\mathrm{CO}_{2}$ atmospheric concentration has an influence on the climate and is taken into account by the climate models, but it has also a direct effect in the tree-growth model, called also fertilization effect because it stimulates the photosynthesis and reduces the water loss through the stomata.

\subsection{Regionalization}

APG simulations cannot be directly used as inputs in the MAIDEN model because they are affected by some systematic biases. They have been corrected with the CRU data at every gridpoint and for every month of the studied period, by using the temporal discrepancies between both data sets over the common period (1960-1997). APG temperatures (resp. precipitations) are corrected by adding to daily values the difference (resp. ratio) between APG and CRU means of the corresponding month. No topographical correction has been applied on APG variable values as both data sets present similar topography.

\subsection{Simulation validation}

R50 index and simulated bole increment for pine species will also be compared in order to assess our model ability to simulate spatial variability of tree-growth, after interpolation using a 2-D bicubic interpolation for southeast France. The assessment of the climate impact on tree-growth is based on the comparison between two periods of 38 years each: 19601997 (hereafter called 20th century period) and 2062-2099 (21st century period). The direct impact of $\mathrm{CO}_{2}$ is based on the comparison on the 21 st century with and without taking into account for the $\mathrm{CO}_{2}$ increase at the input of the MAIDEN model. Runs without $\mathrm{CO}_{2}$ increase means that the $1995 \mathrm{CO}_{2}$ concentration $(360 \mathrm{ppm})$ has been used for the whole 21 st century. The vulnerability of both species is assessed by comparing the maps of their simulations for both periods and the time series of their averaged bole increments.

\section{Results}

\subsection{Ecophysiological and dendrochronological calibration}

The differences (mean absolute values in $\mathrm{mm}$ /day) between observed and simulated transpiration over year 2004 is low and reach $4 \%$ for pine and $6 \%$ for oak (not shown). This discrepancy does not seem to be due to the parameter values as both observation and simulation curves present the same seasonal variations, but rather due to a higher soil depth inducing a lower simulation of the soil water stress. The bole $\mathrm{C}$ allocation of the pine is around $650 \pm 50 \mathrm{~g} / \mathrm{mm}^{2}$ and around $250 \pm 40 \mathrm{~g} / \mathrm{mm}^{2}$ for the oak.

The pine MCMC calibration of MAIDEN model with PACA dendrochronological series shows a modal fit at $r^{2}=0.37 \pm 0.04$ (Fig. 1). This correlation is lower than the one computed in previous works (Misson, 2004), because model has been improved and because the (Bayesian) calibration stage is different and more rigorous (Gaucherel et al., 2008). The oak MCMC calibration of MAIDEN model with the Puéchabon dendrochronological series shows a modal fit at $r^{2}=0.50 \pm 0.06$. The agreement between simulated and observed oak chronologies was good from 1942 to 1990 and 
Table 1. Monthly values of the three climate parameters used (mean maximum and minimum daily temperatures in ${ }^{\circ} \mathrm{K}$ and monthly amount of precipitations in mm) for the common period (1960-1997) between CRU (Climatic Research Unit, University of East Anglia) and APG (ARPEGE model Météo-France) data. Corrected APG values using CRU values are noted APG/CRU. Monthly means (for temperatures) and sums (precipitations) are highlighted in bold with their annual means and standard deviations.

\begin{tabular}{|c|c|c|c|c|c|c|c|c|c|c|c|c|c|c|}
\hline Parameters & $\mathrm{J}$ & $\mathrm{F}$ & $\mathrm{M}$ & $\mathrm{A}$ & $\mathrm{M}$ & $\mathrm{J}$ & $\mathrm{J}$ & A & $\mathrm{S}$ & $\mathrm{O}$ & $\mathrm{N}$ & $\mathrm{D}$ & $\begin{array}{c}\text { Mean }\left(T^{\circ}\right) \text { or } \\
\text { Sum (Pcp) }\end{array}$ & $\begin{array}{c}\text { Month } \\
\text { Std }\end{array}$ \\
\hline$T$ (mean) CRU & 2.05 & 3.09 & 5.42 & 8.03 & 12.01 & 15.60 & 18.54 & 18.18 & 15.13 & 10.88 & 5.74 & 2.80 & 9.79 & 6.09 \\
\hline$T$ max APG/CRU & 4.75 & 7.09 & 10.94 & 15.80 & 22.30 & 28.75 & 33.87 & 33.57 & 25.75 & 14.72 & 4.29 & -1.40 & 16.70 & 12.03 \\
\hline$T$ min APG & -1.18 & -0.52 & 0.62 & 2.79 & 6.09 & 9.69 & 12.72 & 13.43 & 10.51 & 5.89 & 2.52 & 0.18 & 5.23 & 5.28 \\
\hline$T$ min APG/CRU & -0.55 & 0.48 & 3.14 & 6.83 & 12.70 & 18.27 & 22.62 & 21.63 & 15.03 & 6.26 & -1.76 & -6.39 & 8.19 & 9.71 \\
\hline Pcp APG & 56.12 & 47.99 & 60.40 & 72.20 & 95.75 & 86.70 & 74.24 & 58.49 & 59.85 & 88.00 & 82.28 & 74.73 & 857 & 14.91 \\
\hline Pcp APG/CRU & 77.83 & 64.51 & 86.88 & 131.32 & 171.36 & 129.09 & 80.43 & 80.13 & 87.90 & 133.44 & 101.37 & 77.87 & 1222 & 32.10 \\
\hline
\end{tabular}

degraded after, probably under the influence of a biological factor such as the canopy closure. The model overestimated growth in 1996 and 1997, maybe because trees might have shed some leaves during the 1995 extremely dry year. Drought and the reconstruction of the canopy might have necessitated carbohydrates reserves through processes that are not modelled. Conversely, the model seems having overestimated drought effects in 2003 and 2005. Tree-ring width during the 1999-2005 showed a decreasing trend probably due the accumulation of stress such as increasing drought in the nineties, high temperature in 2003 and insect defoliation in 2004 and 2005. In these circumstances, the model seems to show too much interannual variability and to be unable to solve for low frequency growth cycle.

Nevertheless, differences between calibrated bole increment simulations and observations are quite homogeneous, showing the ability of the model to simulate a large variability of growth (Fig. 1), while the oak growth is better fitted than the pine growth. It can be due to the negative trend of the oak growth observed since the beginning of the year 70's. The fact that the model is able to simulate this trend could confirm its climatic origin. As additional and independent validation, gridded pine R50 values and simulated bole increment are compared and show a correct qualitative agreement (Fig. 2). Maxima are located at the centre of both maps, even if R50 have two maxima and simulation maximum is slightly shifted westward by about $30 \mathrm{~km}$.

\subsection{Climate regionalization}

Temperature and precipitation data for CRU and APG climatology are rather similar over the 38 common years in average (Table 1), but the APG simulations are more variable from month to month. Both temperature data sets show a lapse rate of about $-0.0065 \mathrm{~K} / \mathrm{m}$. Spatial temperature and precipitation simulated distribution (not shown) are also more scattered, probably due to the fact that each APG
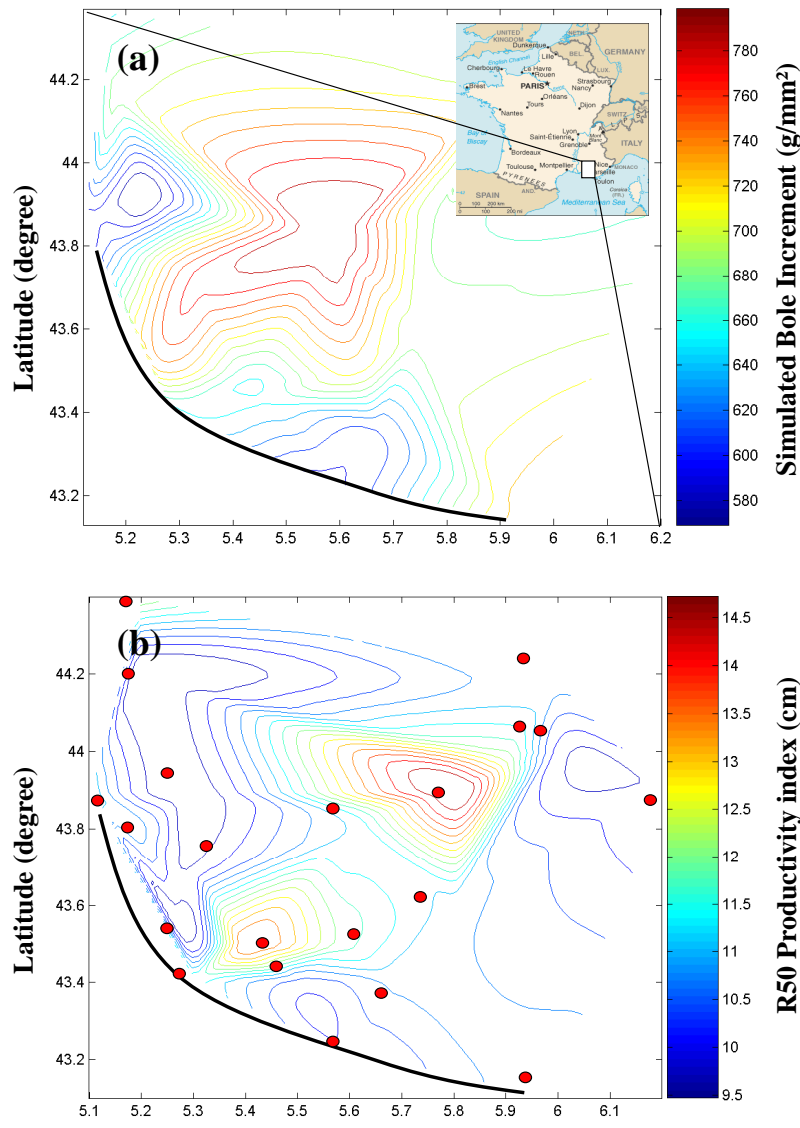

Longitude (degree)

Fig. 2. Map of the simulated bole increments of pine (a) and of the R50 productivity index (b) in PACA southeast France (inset) for the twentieth century. Coastline is highlighted and the 21 pine stands are superimposed on the R50 productivity index map. 

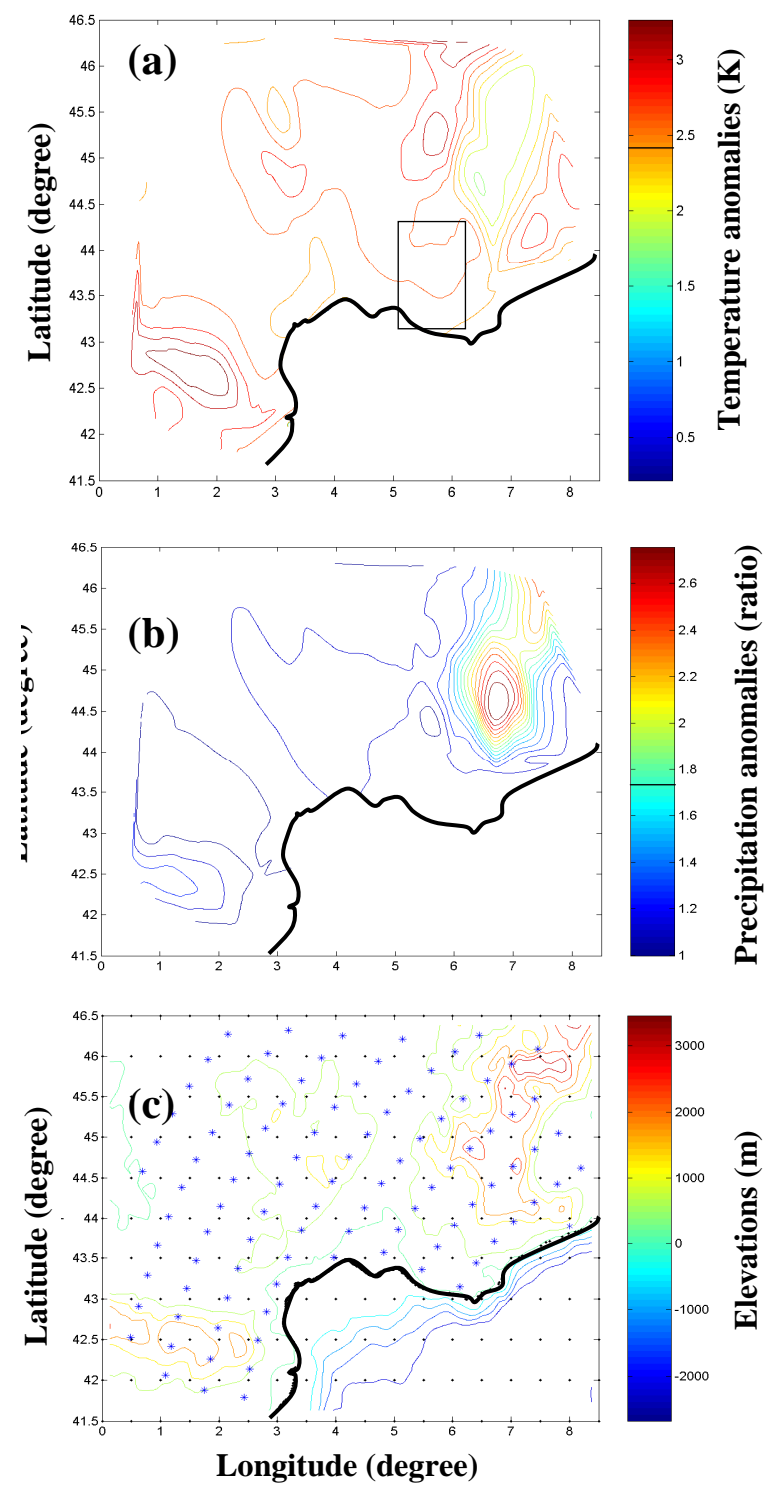

Fig. 3. (a) Map of the mean temperature anomalies (twenty first minus twentieth centuries) simulated by ARPEGE and averaged over the 12 months (in K). (b) Map of the precipitation ratios between twenty first and twentieth century simulated by ARPEGE. Daily precipitation ratios have been averaged by month an then over the year. (c) Topography of southeast France, superimposed with the two ARPEGE (dots) and CRU (stars) $0.5^{\circ} \times 0.5^{\circ}$ grids. The 21 pine stand area (Fig. 2) is located on the temperature anomaly map.

gridpoint is a punctual value rather than a cell-grid average. The mean annual deviation (resp. ratio) between APG and CRU datasets over this control period is $+3.18 \pm 1.68 \mathrm{~K}$ for mean temperature (resp. $0.82 \pm 0.47$ for rainfall) and for the whole studied region. Note that these averaged values are not exactly equal with differences between lines of Table 1 , as calculations before averaging stage are made separately for each grid points and each month.
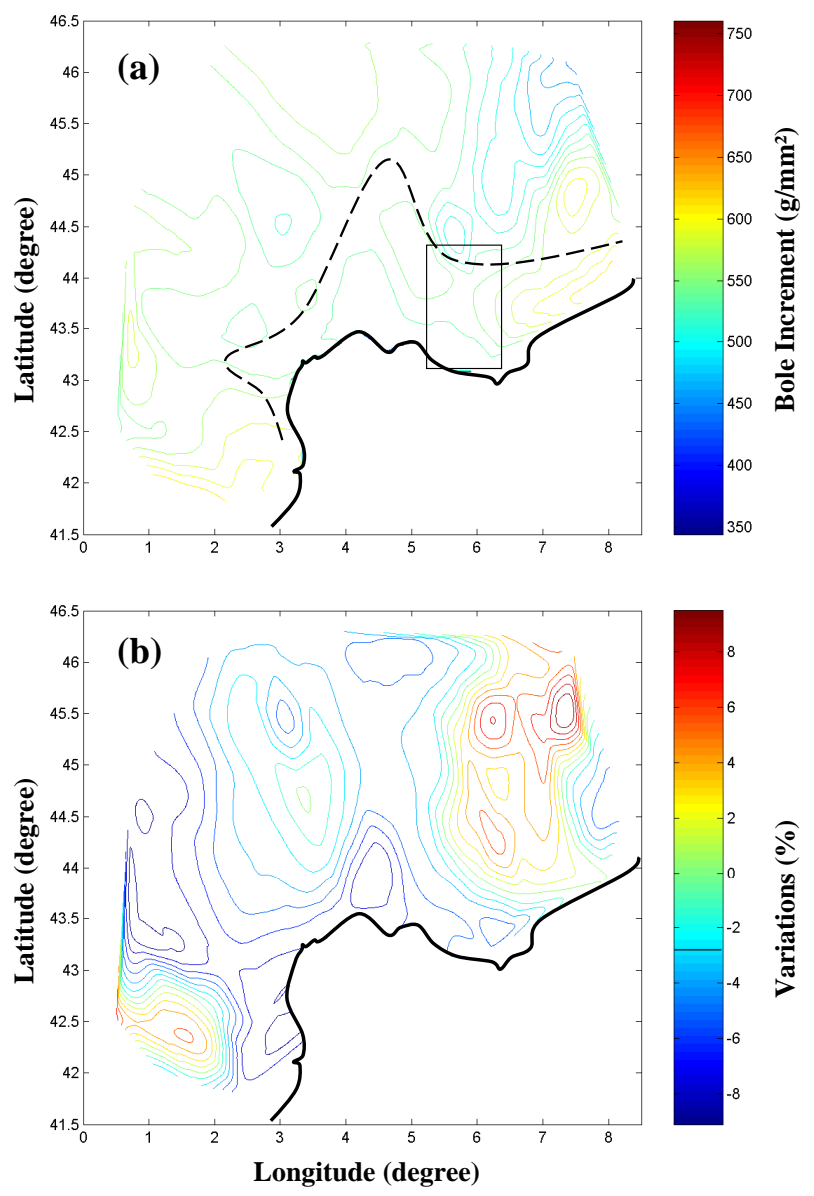

Fig. 4. (a) Map of the mean annual growth of pine in southeast France at the end of the twentieth century (1960-1997). The modern limit of its potential distribution is indicated in black dashed line. (b) Map of the mean annual growth variation of pine in southeast France (in \%), between the twentieth and the twenty first centuries without direct effect of $\mathrm{CO}_{2}$ (i.e. with atmospheric $\mathrm{CO}_{2}$ being fixed to $360 \mathrm{ppm}$ ). The 21 pine stand area (Fig. 2) is located on the bole increment map.

APG simulations for the 21st century are corrected using monthly and spatially dependent deviation (or ratio) coefficients (Table 2). Temperature (Fig. 3a) and precipitation (Fig. 3b) values of the 2062-2099 period are significantly higher than those of the 1960-1997 period. Mean annual deviations of daily maximum and minimum temperatures are $+2.62 \pm 0.66 \mathrm{~K}$ and $+2.27 \pm 0.54 \mathrm{~K}$, respectively, while mean annual precipitation will increase by a factor $1.75 \pm 0.98$. The temperature diurnal amplitude ( $\max -\mathrm{min}$ ) will also decrease with elevation. Precipitation patterns between both periods are very different at high elevations (almost a factor three) and similar at low elevations (Fig. 3b). 
Table 2. Correction coefficients (up) of APG parameters for the twenty-first century based on monthly and spatially dependent deviation (for temperatures) or ratio (for precipitations) coefficients. All coefficients have been computed over the (1960-1997) control period using the whole PACA grid. Mean monthly variations of the corrected climate parameters (down) between the twenty-first and twentieth centuries (noted 21/20) are presented. Annual means and standard deviations of monthly values follow.

\begin{tabular}{|c|c|c|c|c|c|c|c|c|c|c|c|c|c|c|}
\hline Coefficients & $\mathrm{J}$ & $\mathrm{F}$ & M & A & M & $\mathrm{J}$ & $\mathrm{J}$ & A & $S$ & $\mathrm{O}$ & $\mathrm{N}$ & $\mathrm{D}$ & Mean & Std \\
\hline$T(\max$ and $\min )$ & -0.63 & -1.00 & -2.52 & -4.04 & -6.61 & -8.58 & -9.90 & -8.20 & -4.52 & -0.37 & 4.27 & 6.58 & -2.96 & 5.08 \\
\hline Pcp & 1.35 & 1.31 & 1.45 & 1.80 & 1.80 & 1.51 & 1.11 & 1.39 & 1.46 & 1.49 & 1.20 & 1.04 & 1.41 & 0.24 \\
\hline$T \max 21 / 20$ & 2.54 & 2.12 & 2.24 & 2.49 & 2.91 & 2.88 & 4.16 & 3.39 & 2.73 & 1.94 & 1.95 & 2.03 & 2.62 & 0.66 \\
\hline$T \min 21 / 20$ & 2.26 & 1.89 & 1.68 & 1.99 & 2.16 & 2.65 & 3.35 & 2.95 & 2.82 & 1.95 & 1.68 & 1.92 & 2.27 & 0.54 \\
\hline Pcp 21/20 & 2.74 & 4.46 & 1.83 & 1.72 & 1.01 & 1.14 & 0.94 & 1.10 & 1.67 & 1.40 & 1.50 & 1.53 & 1.75 & 0.98 \\
\hline
\end{tabular}

\subsection{Pine growth}

Pine growth simulated for the 20th century with a $\mathrm{CO}_{2}$ concentration increasing from $317 \mathrm{ppm}$ (in 1960) to $360 \mathrm{ppm}$ (1995), as expected, shows less productive zones at higher elevations where temperature is less favorable (Fig. 4a). For the 21 st century, there will be a negligible mean decrease of about $-2.72 \pm 4.57 \%$ compared to the first period. This hides a large spatial variability with increase up to $+8 \%$ at high elevations (Fig. 4b). If we take into account the direct effect of atmospheric $\mathrm{CO}_{2}$ (rising up to $612 \mathrm{ppm}$ at the end of the 21 st century), growth pattern will be very different (Fig. 5a): a mean increase of about $+22.24 \pm 4.14 \%$, with maxima at about $+30 \%$ at intermediate elevations. Moreover, in relative values, low elevations are the most favored by the direct fertilizing effect (Fig. 5b). The average gain due to $\mathrm{CO}_{2}$ is about $+26.01 \pm 3.68 \%$ with a significant relative productivity loss of about $0.8 \%$ per $100 \mathrm{~m}$ elevation (up to the highest grid-point at elevation $2200 \mathrm{~m}$ ). This difference between pine production simulation with and without direct $\mathrm{CO}_{2}$ effect is linear in time and of about $0.34 \%$ per year. With $\mathrm{CO}_{2}$ direct effect too, pine production is maximum at intermediate elevation, where the climate is a transition between warm and dry plains and cool and wet mountains (Fig. 5a). Pine growth seems to be optimum nowadays for elevation comprised below $800 \mathrm{~m}$ (Fig. 6a), while this optimum is shifted up to $1100 \mathrm{~m}$ for the 21 st century (Fig. 6b), whatever is the $\mathrm{CO}_{2}$ factor used. The twenty-year window moving average curves (Fig. 7a) show that pine growth reaches a maximum for present if we keep $\mathrm{CO}_{2}$ constant during the 21 st century, while it continues to increase if $\mathrm{CO}_{2}$ increases according to the IPCC B2 scenario. The productivity increase seems to be constant, or weakly slowing down, at the end of 21 st century (Fig. 7a). This increase over 100 years reaches 30\% in average for the region, with a maximum at intermediate elevation. The present distribution of both species only covers a small fraction of these potential areas (approximately 15\% for pine and 25\% for oak) (Figs. 5a and 8a, dashed lines).
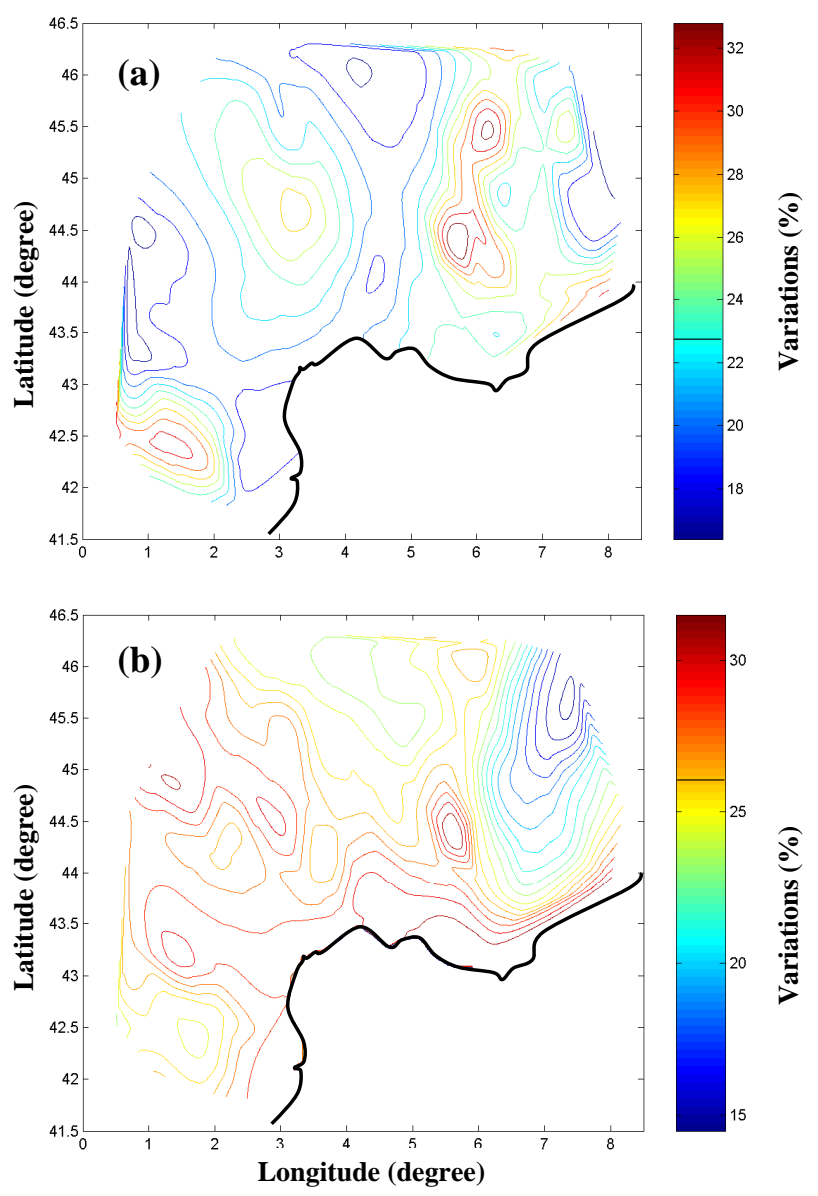

Fig. 5. (a) Map of the mean annual growth variation of pine in southeast France (in \%), between the twentieth (1967-1997) and the twenty first (2062-2099) centuries with direct effect of $\mathrm{CO}_{2}$ (increasing from 360 to $612 \mathrm{ppm}$ ). (b) Difference of pine growth between simulations with and without increase of $\mathrm{CO}_{2}$ in twenty first century. 

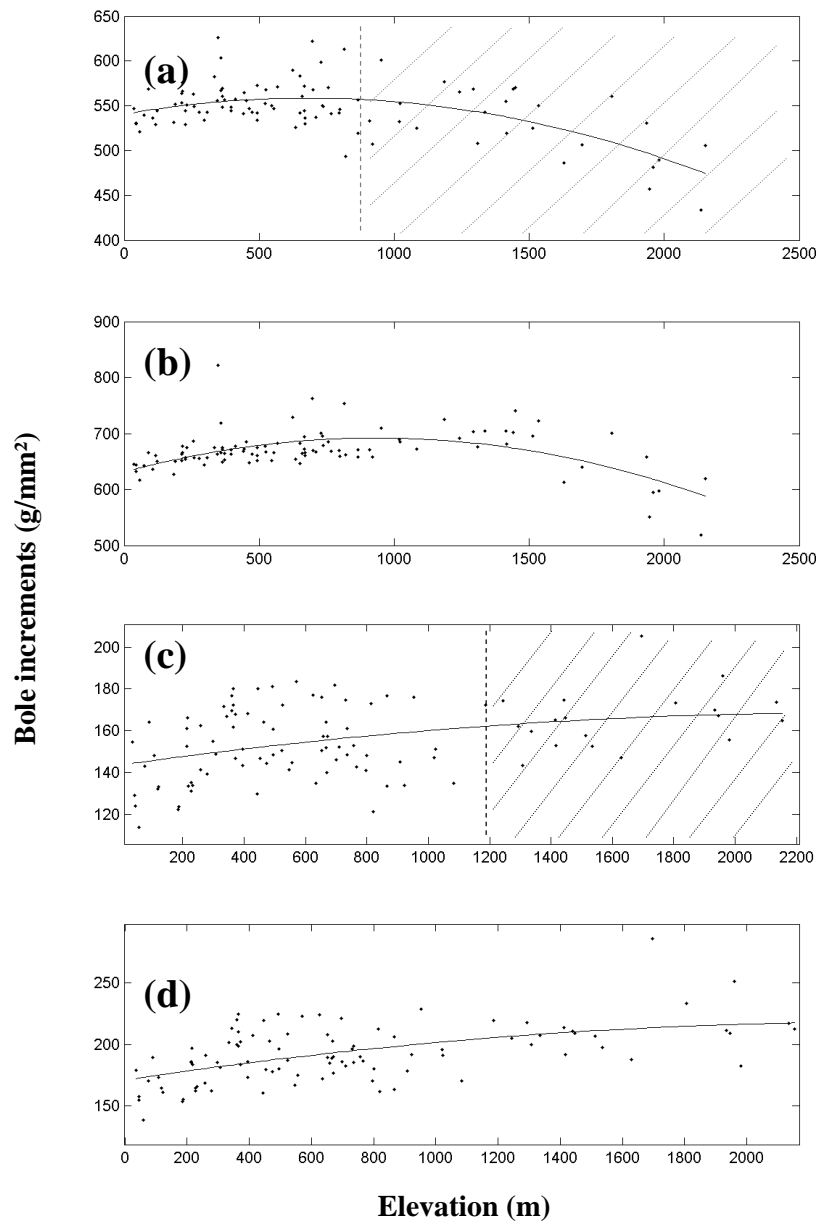

Fig. 6. Relationships between mean annual growth of pine (resp. oak) and elevation: (a) pine, twentieth century, (b) pine, twenty first century with $\mathrm{CO}_{2}$ direct effect, (c) oak, twentieth century, (d) oak, twenty first century with $\mathrm{CO}_{2}$ direct effect. The elevation range where pine and oak are not living at present time is indicated by hashes.

\subsection{Oak growth}

Simulations of oak growth for 20th century without $\mathrm{CO}_{2}$ direct effect show a weak spatial variability and much lower (two times) productivity than pine (Fig. 8a). Oak mean growth simulation during the 21st century period decreases by about $-13.8 \pm 4.8 \%$ compared to the control period, but reaches a value of $-25 \%$ in some low elevation zones (Fig. 8b). The differences between both periods are much more important for oak than for pine. If we include the direct effect of atmospheric $\mathrm{CO}_{2}$ (Fig. 9a), mean oak growth increases by about $+24.1 \pm 5.6 \%$ and reaches a value of about $+43 \%$ at high elevations. The spatial distribution is quite homogenous regarding to the elevation factor. Oak does not show any optimum with elevation (Fig. 6c, d). The gain due to $\mathrm{CO}_{2}$ direct effect is optimum at low elevations (Fig. 9b). As highlighted by the twenty-year window moving average
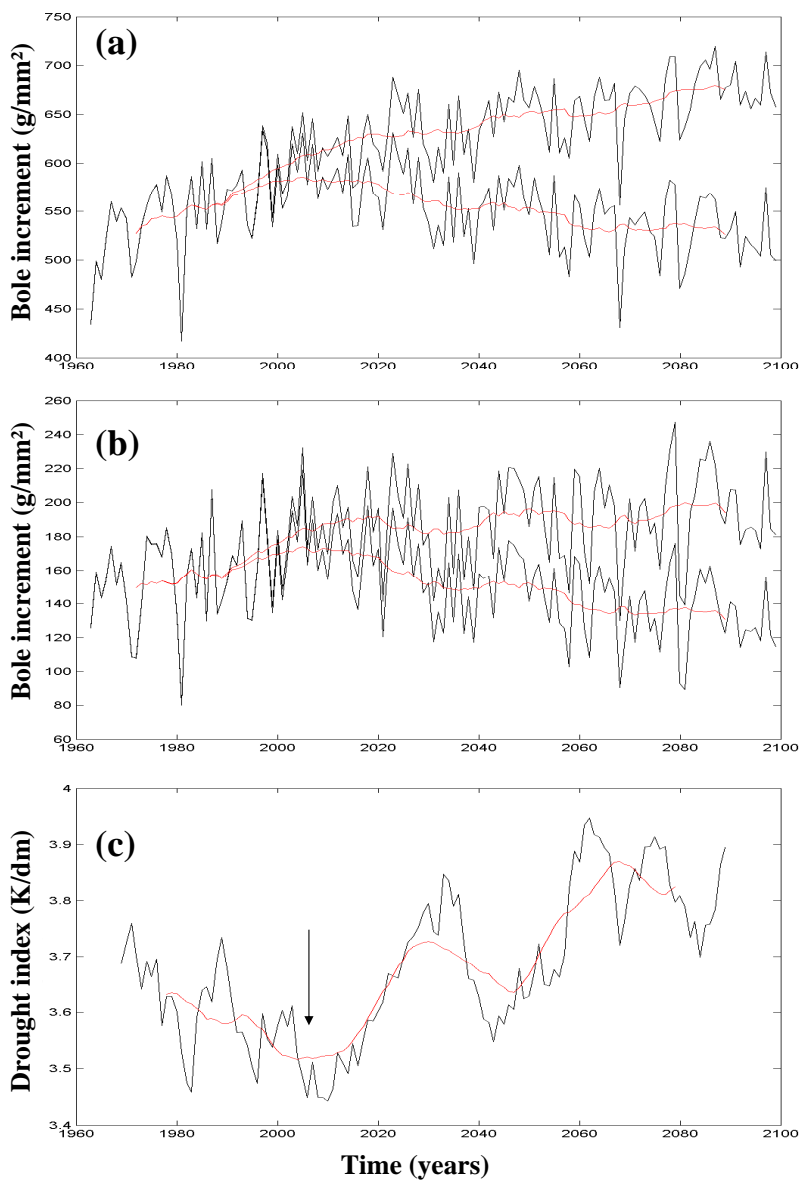

Fig. 7. (a) Evolution of the mean annual production of pine for southeast France simulated on the basis of the ARPEGE scenario, with (plain line) and without (dotted line) direct effect of $\mathrm{CO}_{2}$. (b) Same for oak. (c) Evolution of a simple drought index (annual temperature in $\mathrm{K}$ divided by annual total of precipitation in $\mathrm{mm}$ ). The red curves correspond to 20 year window moving averages.

curve, the trend of regional oak growth with and without $\mathrm{CO}_{2}$ direct effect (Fig. 7b), has the same general behavior than for pine: a progressive productivity increase throughout the 21st century with $\mathrm{CO}_{2}$ direct effect versus a decrease with constant $\mathrm{CO}_{2}$. This increase over 100 years reaches $50 \%$ in average for the region, and even more at low elevation. Tree growth evolution for constant $\mathrm{CO}_{2}$ concentration reaches a maximum around year 2005 for both species (Fig. 7). The simplified drought index of Fig. 6c (temperature/precipitation ratio) smoothed with a twenty year moving window confirms that the period around 2005 is simulated as the most humid of the analyzed period. Afterwards, drought increases considerably, inducing an important growth deficit if $\mathrm{CO}_{2}$ direct effect does not compensate it. 

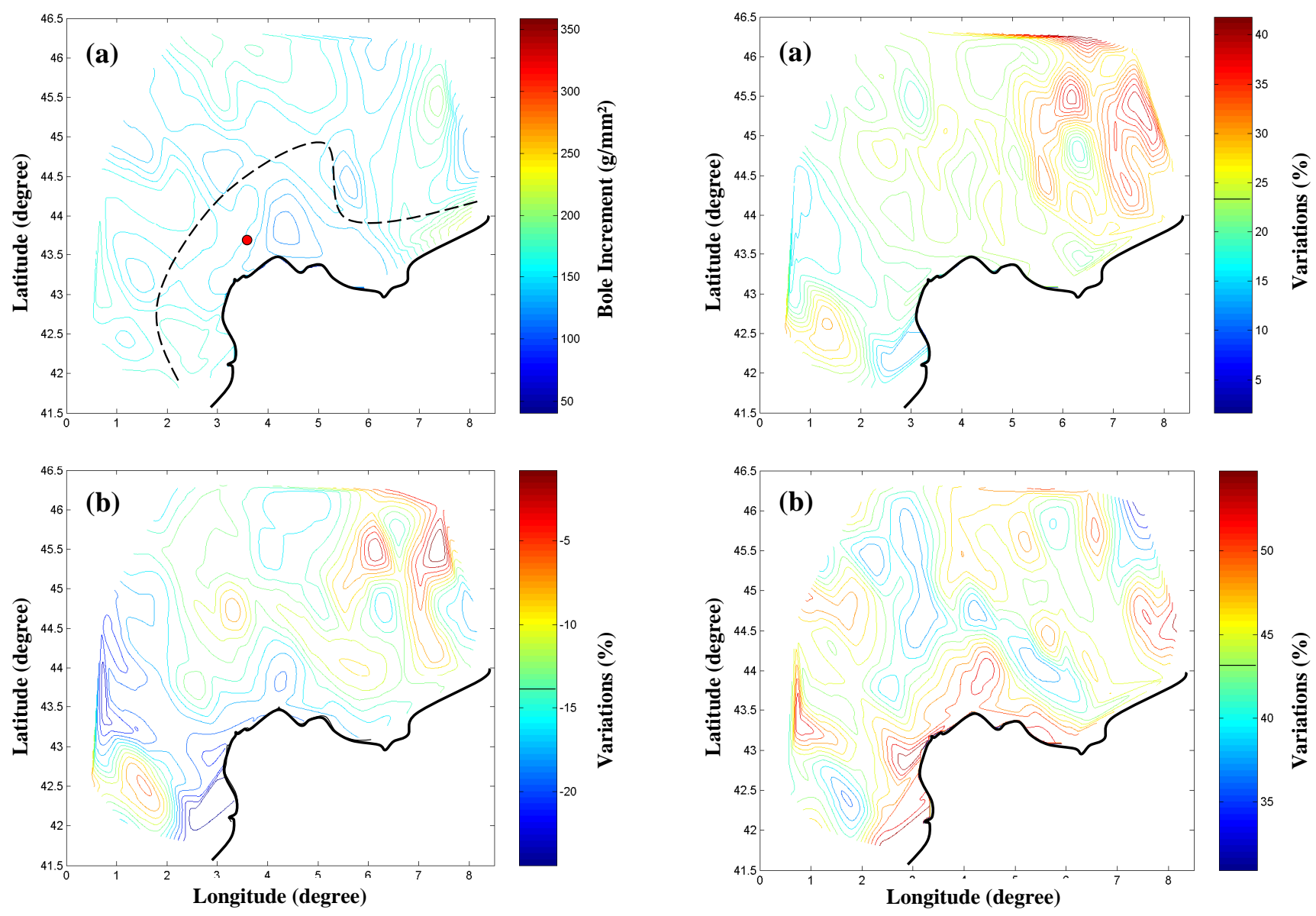

Fig. 8. (a) Map of mean annual growth of oak in southeast France at the end of the twentieth century (1960-1997); the modern limit of its potential distribution is indicated in black dashed line and the Puéchabon site is located (red dot). (b) Map of the variation of the mean annual growth of oak in southeast France (in \%), between the twentieth and the twenty first centuries without direct effect of $\mathrm{CO}_{2}$ (i.e. with $\mathrm{CO}_{2}$ being fixed to $360 \mathrm{ppm}$ ).

\section{Discussions}

\subsection{Climate and growth modelling}

The distribution of precipitation corrections (computed between CRU and APG data sets for the twentieth reference period) is highly heterogeneous in space (Fig. 3b). This is possibly due to difficulties to precisely simulate frequent and local raining events in Mediterranean climate (West et al., 1986). The precipitation changes are only significantly positive above $500 \mathrm{~m}$, for the benefit to the tree growth. This is obvious for Alps and in a much lower extent for Pyrenees mountains. For temperature, Alps and Pyreneans do not behave in the same way: temperature anomalies will decrease with elevation in the Alps, and increase in the Pyreneans (not shown), amplifying so the constraints.

Fig. 9. (a) Map of the variation of the mean annual growth of Quercus Ilex in Southeast France (in \%), between the Twentieth (19671997) and the twenty first centuries with direct effect of $\mathrm{CO}_{2}$ (increasing from 360 to $612 \mathrm{ppm}$ ). (b) Difference of oak growth between simulations with and without increase of $\mathrm{CO}_{2}$ in twenty first century (2062-2099).

The MAIDEN model, after calibration, has shown a correct ability to simulate tree growth of pine and oak species under various environmental conditions (Fig. 1). Some previous works succeeded in such modeling using remote sensing (LAI) calibration (Anselmi et al., 2004). Our approach is, in a way, different and original, as we have calibrated a complex ecophysiological model, using dendrochronological time series (Gaucherel et al., 2008). The simulations are generally realistic from 1960 to 1997 . But some short periods (such as 1985-1987) are poorly simulated, mainly due to factors not included in the model, as cold winters that could have damaged the cambium cells of tree bole. The model calibration is based on the mean regional tree-ring chronology, and an independent validation has been designed on the spatial variability of the tree-growth. The spatial distribution of the pine R50 indices has been successfully compared to the spatial distribution of the simulations. 
Tree growth simulations are only regional trends and are still too broad to take into account for detailed abiotic factors such as soil characteristics. Nevertheless, spatial and temporal trends have been clearly identified. If we do not take into account for $\mathrm{CO}_{2}$ fertilization effect, we find that tree growth has reached a maximum around year 2005 for both species (Fig. 7): this should not be taken as a precise date for the optimum of these species; it rather shows that the climate changes will not beneficiate to these species in the future in terms of ecophysiological processes at large scales in average.

Some assumptions made in this work have to be discussed. Simulated distribution areas are potential distributions, which do not taken into account any history of species colonization nor human influences (Debussche et al., 1999). The present distribution of both species, only covering a small fraction of their potential areas (Figs. $5 \mathrm{a}$ and $8 \mathrm{a}$, dashed lines), will likely extend or shift during the coming decades, as it has been simulated for example for broadleaf forests in China by similar approaches (Yu et al., 2002). For clarity too, we have chosen not hiding on maps high elevations at which tree species would not be able to grow due to freeze. Furthermore, another hypothesis behind our results is that there is no population dynamics included in the model, such as metapopulation processes (Rétho et al., 2008), and that species colonization is more rapid than climate dynamics. In case of low colonization rate, the driving factor of the potential distribution is no longer the climate, but the dispersion rate and its modulation by environmental factors (Hanski and Ovaskainen, 2000). Our simulations, mainly based on climate, are then indicative and not predictive.

\subsection{Environmental factors}

Topography and climate effects: the pine species production shows a significant optimum for intermediate elevations (around $650 \mathrm{~m}$, Fig. 6a), indicating that pine does not accommodate with low temperatures. The oak species production increases with elevation without any optimum, thus directly beneficiating of precipitation increase in mountainous areas (Fig. 6c). Several processes that are not taken into account in our simulations are able to stop the oak progression at higher elevations: competition with other species and embolism of main vessels after winter colds. Our model simulates a shift of the pine production optimum at about $950 \mathrm{~m}$ (Fig. 6b), due to $2.5 \mathrm{~K}$ temperature increase. This is particularly true if temperature during the warm part of the year is the main control of forest limit in temperate zones (Jobbagy and Jackson, 2000). Climate is changing, with frost frequencies potentially changing too. It is probable that frost will be rarer and will favour colonization at higher elevations too. With this respect, we kept as much information as possible and we did not masked distribution areas computed (Figs. 5 and 9). Finally, both species will be favored during the twenty first century and will likely colonize higher elevations than occu- pied today, but for different reasons: pine species will climb up because it does not yet reached its productivity optimum, oak species because it probably has no optimum.

$\mathrm{CO}_{2}$ concentration: without any direct fertilization effect of atmospheric $\mathrm{CO}_{2}$, both species show weak changes in their distribution area: -3 and $-14 \%$ for pine and oak respectively in average for the region (Figs. $4 \mathrm{~b}$ and $8 \mathrm{~b}$ ). At least is it hard in our simulations to maintain species in plains (particularly for oak species). With the direct effect of $\mathrm{CO}_{2}$, both species have a significant increase in productivity: +26 and $+43 \%$ for pine and oak respectively (Figs. 5b, 9b). This fertilizing effect even, on the basis of our data and modeling, has a stronger impact than climate change. Higher $\mathrm{CO}_{2}$ concentration allows the tree to close its stomata, leading to a better efficiency in the water use, even if the water budget decreases, such as after year 2030. We are confident about the simulation of this forcing because $\mathrm{CO}_{2}$ fertilizing effect has been calibrated and validated by using the observed atmospheric $\mathrm{CO}_{2}$ concentrations for the 20th century. In addition, the direct effect of $\mathrm{CO}_{2}$ tends to reinforce the productivity/topography relationships and in particular the oak $\left(r^{2}\right.$ shifting from 0.38 to 0.54$)$. Finally, the direct effect of $\mathrm{CO}_{2}$ will modify deeply the distribution areas of both species. Both species will certainly maintain in plains at low elevations, mainly thanks to the $\mathrm{CO}_{2}$ fertilization, but this is more heterogeneous in space for oak species (Figs. 5b, 9b).

\subsection{Species comparison (Oak - Pine)}

For pine and oak species, productivity increases by about +22 and $+26 \%$ in the twenty first century under direct effect of $\mathrm{CO}_{2}$. Both productivities will increase at a rate of about $0.35 \%$ per year (Fig. 7 ). Nevertheless, model simulates a climatic optimum elevation at about $1000 \mathrm{~m}$ for pine while such optimum is not modeled for oak. This difference is probably due to the way each species beneficiate of temperature and precipitation. These species are representative of two functional types extensively found in the Mediterranean: the oak is an evergreen sclerophyllous often found in secondary successions, and the pine is drought-adapted conifer and a colonizing species. They have a very different physiological response to drought, which lead to contrasted ecosystem functioning: P. halepensis is typically drought-avoiding water-saving, whereas $Q$. ilex is more tolerant to precipitation variability (Ferrio et al., 2003; Martinez-Ferri et al., 2000; Methy et al., 1997). P. halepensis develops very well in dry environment, but might be less competitive in higher altitude where precipitation is high and temperature is low. Note here that our ecophysiological model does not limit tree growth at high elevations because freeze induced embolism is an effect not taken into account.

Our results also have limitations linked to both data and models. Our measurements still do not cover optimum periods of time. The vegetation models have some lacunae which must be filled up progressively in future. Finally, our 
vulnerability studies are based on a single scenario (IPCCB2) of a single climatic model. They therefore do not have value of prediction but simply of indication. It will be necessary, to complete this approach, to use simulation ensembles from several climate models to deal with the climate evolution under probabilistic forms.

\section{Conclusion}

Finally, considering their present distribution areas being mainly located in the central part of PACA region and at low elevations, pine and oak species have a good chance, according to our data and modeling, to extend their habitat. This general trend is mainly (but not only) caused by the $\mathrm{CO}_{2}$ atmospheric increase. Pine should colonize eastward and southward (along to Alps and Pyrenees slopes), while oak should colonize eastward, in the Alps. While our model does not simulate species competition, nor embolism, the pine productivity optimum with elevation should favor this species in a first stage and then leave the place for oak, in particular at higher (above $1000 \mathrm{~m}$ ) elevations.

Acknowledgements. We gratefully thank Cyrille Rathgeber and Yves Gally for comments on earlier drafts or for help in computing developments respectively. This research has been funded by the French program GICC2 (Ministère de l'Ecologie et du Développement Durable) (project REFORME, 2005-2007) and by the Agence Nationale de la Recherche (project DROUGHT+, ANR-06-VULN-003-01).

Edited by: J. Leifeld

\section{References}

Andrieu, C., Djuric, P. M., and Doucet, A.: Model selection by mcmc computation, Signal Processing, 81, 19-37, 2001.

Anselmi, S., Chiesi, M., Giannini, M., Manes, F., and Maselli, F.: Estimation of mediterranean forest transpiration and photosynthesis through the use of an ecosystem simulation model driven by remotely sensed data, Global Ecology and Biogeography, 13, 371-380, 2004.

Ciais, P., Reichstein, M., Viovy, N., Granier, A., Ogee, J., Allard, V., Aubinet, M., Buchmann, N., Bernhofer, C., Carrara, A., Chevallier, F., De Noblet, N., Friend, A. D., Friedlingstein, P., Grunwald, T., Heinesch, B., Keronen, P., Knohl, A., Krinner, G., Loustau, D., Manca, G., Matteucci, G., Miglietta, F., Ourcival, J. M., Papale, D., Pilegaard, K., Rambal, S., Seufert, G., Soussana, J. F., Sanz, M. J., Schulze, E. D., Vesala, T., and Valentini, R.: Europe-wide reduction in primary productivity caused by the heat and drought in 2003, Nature, 437, 529-533, 2005.

Cook, E. R. and Kairiukstis, L. A.: Methods of dendrochronology, applications in the environmetal sciences, Kluwer Academic Press, Dordrecht, 394 pp., 1990.

Debussche, M., Lepart, J., and Dervieux, A.: Mediterranean landscape changes: Evidence from old postcards, Global Ecology and Biogeography, 8, 3-15, 1999.
Deque, M., Dreveton, C., Braun, A., and Cariolle, D.: The arpege/ifs atmosphere model - a contribution to the french community climate modeling, Clim. Dynam., 10, 249-266, 1994.

Eamus, D., Macinnis-Ng, C. M. O., Hose, G. C., Zeppel, M. J. B., Taylor, D. T., and Murray, B. R.: Ecosystem services: An ecophysiological examination, Australian J. Botany, 53, 1-19, 2005.

Ferrio, J. P., Florit, A., Vega, A., Serrano, L., and Voltas, J.: Delta c13 and tree-ring width reflect different drought responses in quercus ilex and pinus halepensis, Oecologia, 137, 512-518, 2003.

Gaucherel, C., Campillo, F., Misson, L., Guiot, J., and Boreux, J. J.: Parameterization of a process-based tree-growth model: Comparison of optimization, mcmc and particle filtering algorithms, Environm. Model. Software, 23, 1280-1288, 2008.

Gelman, A., Carlin, J. B., Stern, H. S., and Rubin, D. B.: Bayesian data analysis, Chapman \& Hall, London, 526 pp., 1995.

Gibelin, A. L. and Deque, M.: Anthropogenic climate change over the mediterranean region simulated by a global variable resolution model, Clim. Dynam., 20, 327-339, 2003.

Giorgi, F.: Climate change hot-spots, Geophys. Res. Lett., 33, L08707, doi:10.1029/2006GL025734, 2006.

Granier, A.: Une nouvelle méthode pour la mesure du flux de sève brute dans le tronc des arbres, Ann. For. Sci., 42, 193-200, 1985.

Granier, A.: Evaluation of transpiration in a douglas-fir stand by means of sap flow measurements, Tree Physiology, 3, 309-320, 1987.

Guiot, J.: Arma techniques for modelling tree-ring response to climate and for reconstructing variations of palaeoclimates, Ecological Modelling, 33, 149-171, 1986.

Hanski, I. and Ovaskainen, O.: The metapopulation capacity of a fragmented landscape, Nature, 404, 755-758, 2000.

Jobbagy, E. G. and Jackson, R. B.: Global controls of forest line elevation in the northern and southern hemispheres, Global Ecology and Biogeography, 9, 253-268, 2000.

Joffre, R., Rambal, S., and Damesin, C.: Functional attributes in mediterranean-type ecosystems, in: Handbook of functional plant ecology, Marcel Dekker Inc., New York, 347-380, 1999.

Luoto, M., Poyry, J., Heikkinen, R. K., and Saarinen, K.: Uncertainty of bioclimate envelope models based on the geographical distribution of species, Global Ecology and Biogeography, 14, 575-584, 2005.

Martinez-Ferri, E., Balaguer, L., Valladares, F., Chico, J. M., and Manrique, E.: Energy dissipation in drought-avoiding and drought-tolerant tree species at midday during the mediterranean summer, Tree Physiology, 20, 131-138, 2000.

Methy, M., Gillon, D., and Houssard, C.: Temperature-induced changes of photosystem ii activity in quercus ilex and pinus halepensis, Can. J. For. Res.-Revue Canadienne De Recherche Forestiere, 27, 31-38, 1997.

Misson, L.: Maiden: A model for analyzing ecosystem processes in dendroecology, Can. J. For. Res.-Revue Canadienne De Recherche Forestiere, 34, 874-887, 2004.

Misson, L., Rathgeber, C., and Guiot, J.: Dendroecological analysis of climatic effects on quercus petraea and pinus halepensis radial growth using the process-based maiden model, Can. J. For. Res.Revue Canadienne De Recherche Forestiere, 34, 888-898, 2004.

New, M., Hulme, M., and Jones, P. D.: Representing twentieth century space-time climate variability. Part 1: Development of a 1961-90 mean monthly terrestrial climatology, J. Climate, 12, 
829-856, 1999.

Nicault, A.: Analyse de l'influence du climat sur les variations interet intra-annuelles de la croissance radiale du pin d'alep (pinus halepensis mill.) en provence calcaire, Aix-Marseille III, Marseille, FR, 1999.

Prentice, I. C. and Webb, T.: Biome 6000: Reconstructing global mid-holocene vegetation patterns from palaeoecological records, J. Biogeogr., 25, 997-1005, 1998.

Rambal, S., Ourcival, J. M., Joffre, R., Mouillot, F., Nouvellon, Y., Reichstein, M., and Rocheteau, A.: Drought controls over conductance and assimilation of a mediterranean evergreen ecosystem: Scaling from leaf to canopy, Global Change Biol., 9, 18131824, 2003.

Rathgeber, C., Nicault, A., Guiot, J., Keller, T., Guibal, F., and Roche, P.: Simulated responses of pinus halepensis forest productivity to climatic change and co2 increase using a statistical model, Global Planet. Change, 26, 405-421, 2000.

Rathgeber, C., Nicault, A., Kaplan, J. O., and Guiot, J.: Using a biogeochemistry model in simulating forests productivity responses to climatic change and co2 increase: Example of pinus halepensis in provence (south-east france), Ecol. Model., 166, 239-255, 2003.

Rathgeber, C. B. K., Misson, L., Nicault, A., and Guiot, J.: Bioclimatic model of tree radial growth: Application to the french mediterranean aleppo pine forests, Trees-Structure and Function, 19, 162-176, 2005.

Rétho, B., Gaucherel, C., and Inchausti, P.: Spatially explicit population dynamics of pterostichus melanarius i11. (coleoptera: Carabidae) in response to changes in the composition and configuration of agricultural landscapes, Landscape and Urban Planning, 84, 191-199, 2008.
Running, S. W., Nemani, R. R., and Hungerford, R. D.: Extrapolation of synoptic meteorological data in mountainous terrain and its use for simulating forest evapotranspiration and photosynthesis, Can. J. For. Res.-Revue Canadienne De Recherche Forestiere, 17, 472-483, 1987.

Sitch, S., Smith, B., Prentice, I. C., Arneth, A., Bondeau, A., Cramer, W., Kaplan, J. O., Levis, S., Lucht, W., Sykes, M. T., Thonicke, K., and Venevsky, S.: Evaluation of ecosystem dynamics, plant geography and terrestrial carbon cycling in the lpj dynamic global vegetation model, Global Change Biol., 9, 161185, 2003.

Spiegelhalter, D. J., Thomas, A., and Gilks, W. R.: Bugs, bayesian inference using gibbs sampling, MRC Biostatistics Unit, Cambridge, UK, 1993.

Tessier, L.: Spatio-temporal analysis of climate tree-ring relationships, The New Phytologist, 111, 517-529, 1989.

Thuiller, W., Lavorel, S., Midgley, G. F., Lavergne, S., and Rebelo, A. G.: Relating plant traits and species distributions along bioclimatic gradients for 88 leucadendron species in the cape floristic region, Ecology, 85, 1688-1699 (1683, 1701), 2004.

Vincke, C., Granier, A., Breda, N., and Devillez, F.: Evapotranspiration of a declining quercus robur (1.) stand from 1999 to 2001. Ii. Daily evapotranspiration and soil water reserve, Ann. For. Sci., 62, 615-623, 2005.

West, A. W., Ross, D. J., and Cowling, J. C.: Changes in microbial $\mathrm{c}, \mathrm{n}, \mathrm{p}$ and atp contents, numbers and respiration on storage of soil, Soil Biol. Biochem., 18, 141-148, 1986.

Yu, M., Gao, Q., Liu, Y. H., Xu, H. M., and Shi, P. J.: Responses of vegetation structure and primary production of a forest transect in eastern china to global change, Global Ecol. Biogeogr., 11, 223-236, 2002. 